\title{
An Assessment of MODIS Collection 5 Global Land Cover Product for Biological Conservation Studies
}

\author{
Lu Liang, Peng Gong* \\ State Key Laboratory of Remote Sensing Science, Jointly Sponsored by Institute of Remote Sensing Applications, Chinese \\ Academy of Sciences, and Beijing Normal University \\ Beijing, China \\ *Corresponding author: gong@irsa.ac.cn
}

\begin{abstract}
Global land cover is the characterizations of Earth's surface, and it has been recognized as key drivers of biodiversity changes. Most biological conservation studies are focused on using land cover data to study the pattern of biological environment. However, few studies considered the accuracy of land cover products, which may induce further errors. Ecologists should be aware of those problems before usage. Former comparative analysis only measures the disagreements between different land cover products. But it can not assess the accuracy for individual dataset, due to the differences in classification scheme and cartographic standards. A better way to analyze the uncertainties in land cover products is to use dataset with same input data source, legend, and classifiers. Modis Collection 5 global land cover dataset is the latest version of land cover type product, including eight annual land cover layer from 2001 to 2008 . In this paper, we identified the uncertain areas and figured out the problematic land cover types in this dataset without ground validation samples. Results show that unreasonable changes are concentrated in six main regions, and mostly are in mountain areas and transition zones. The most confusing land cover types are herbaceous and shrub, woody, cultivated land, since they are highly mixable in feature space. Future ecological applications should be aware of these areas and types, and more efforts should be devoted into developing new methods and tools in promoting accuracy of those particular areas and types.
\end{abstract}

Keywords-Modis; land cover data; spatial uncertainty; biological conservation

\section{INTRODUCTION}

Specific land covers or land management practices are important in sustaining particular patterns of biodiversity, and land use change and transformations are considered as key drivers of biodiversity changes at global, national and local scales [1-4]. As Chapin and Sala et al. indicated, by 2100, the impact of land use change on biodiversity is likely to be more significant than climate change $[1,5]$. The mutual interdependencies between land cover, use and biodiversity are becoming the focus of much current researches. Land cover products, which were designed to support scientific investigations that require information related to the state in global land cover properties, had been applied in many biodiversity conservation researches. Walter Jetz et al. utilized Global Land Cover 2000 database to refine the extent of occurrence maps of 8750 species of land birds [6]. Nicholas C. Coops et al. indicated that land cover may be the driving variable of breeding bird species richness at provincial scale [7]. Raquel
Ribeiro suggested a clear relationship between land use and reptile's biodiversity at mesoscale [8].

However, uncertain areas and poorly performed types in classification results are seldom analyzed and discussed in those studies, which may induce bias in further results. Some land cover products provide overall accuracy report. For example, the area-weighted global accuracy of IGBP DisCover dataset produced was $66.9 \%$ [9]; the accuracy of GLC2000 product was 68.6\% [10]; and Modis Land Cover team reported per-class user's accuracies in the range from 60 to $90 \%$, with the overall area-weighted global accuracy estimated at $78.3 \%$ [11]. Validation done by others reported even lower accuracies [12 14]. For biologists, a clear understanding of the spatial distribution of uncertainties and errors is important. In that way, they can conveniently use data with stable classification results, and abandon the data in misclassified areas, or replace them with ancillary information.

Till now, no accuracy map describing the potential false areas in global land cover products was available. Under most condition, accuracy test of land cover products was carried out by using ground designed based sampling. However, this is laborious, and currently only DISCover [9] and GLC2000 [10] had been validated in this way. Comparative analysis between different land cover datasets can be a substitution method, and many efforts have been devoted [15-16]. Normally, areas of disagreement have a higher misclassification probability. However, been prepared by different producers, the disagreement can be induced from the classification mistakes existed in each dataset, or caused by the differences in classification scheme, and cartographic standards such as minimum mapping unit, land feature generalizations, and geolocation framework [18]. Besides, it is hard to infer the error areas in one product from the disagreement areas among different products. But in biological conservation studies, usually only one product is used. In that way, it is better to analyze the uncertainties in land cover products by using dataset with same input data source, legend, and classifiers. Late 2008, Modis released a new product, the Modis Collection 5 Global Land Cover dataset with time series data from 2001 to 2008. Compared with other Modis land cover products, the algorithm and input datasets in Collection 5 have been substantially revised, and its $500 \mathrm{~m}$ spatial resolution is the finest. This time series data with the same input data source, legend, and classifiers can be used as an example in land cover product assessment. 
Another problem is the legend inconsistency in biological studies and land cover products. The choice of legend for different land cover products depends on the requirements and preferences of their producers. For example, Modis land cover data primarily used the IGBP classification system [15]. This system includes 17 general land cover classes defined to meet the needs of IGBP core science projects [19], mainly aimed at modelling $\mathrm{N}_{2} \mathrm{O}, \mathrm{CH}_{4}$ and $\mathrm{CO}_{2}$ fluxes [20], and for biogeochemical studies. The GLC2000 used a flexible classification system developed by FAO and UNEP, which is aimed at providing a valuable common land cover language for building land cover legends. None database was specially designed for biological conservation, and legend used in land cover products can not be directly compared with habitat described by ecologists. IUCN Red List published a three-level hierarchy habitats classification scheme to describe the major habitats in which taxa occur. The first level can be projected to the generalized classes of land cover products. For convenient application, we aggregated the Modis land cover products into eight classes to get in accordance with the IUCN habitats classification scheme.

In this paper, we would like to measure the general patterns of inconsistency, assess the uncertainties existed in Modis land cover products, and highlight the problematic land cover types. This assessment could not only be used in biological studies, but also provide information for data producers to help identify issues for further improvement in land cover mapping.

\section{DATA}

The MODIS Collection5 Land Cover Type product (MCD12Q1) describes land cover properties derived from observations spanning a year's input of Terra and Aqua data, and is generated on a calendar year basis. The algorithm inputs include seven spectral bands, twelve sets of 32-day average nadir BRDF-adjusted reflectance, land surface temperature, and enhanced vegetation index. The classification method is an ensemble supervised approach using 1860 training sites across land [21]. Five classification schemes are contained. The primary scheme identifies 17 land cover classes defined by IGBP, which includes 11 natural vegetation classes, 3 developed and mosiacked land classes, and 3 non-vegetated land classes [19].

The $500 \mathrm{~m}$ spatial resolution data were acquired from the Earth Observing System Data Gateway. The data, which are available in Hierarchical Data Format, were downloaded as tiles in Sinnusoidal projection. The individual tiles were mosaicked together for global coverage and then 17 classes in IGBP layer were generalized into 8 major land cover classes (Table 1).

Table 1. IGBP Land Cover Classes in MCD12Q1

\begin{tabular}{|c|c|}
\hline Aggregated classes & IGBP class \\
\hline \multirow{2}{*}{ Water/wetland } & Water \\
\cline { 2 - 2 } & Permanent wetlands \\
\hline \multirow{2}{*}{ Woody/trees } & Evergreen Needleleaf forest \\
\cline { 2 - 2 } & Evergreen Broadleaf forest \\
\cline { 2 - 2 } & Deciduous Needleleaf forest \\
\hline
\end{tabular}

\begin{tabular}{|c|c|}
\hline \multirow{2}{*}{ Shrub } & Deciduous Broadleaf forest \\
\cline { 2 - 2 } & Mixed forest \\
\cline { 2 - 2 } & Closed shrublands \\
\hline \multirow{2}{*}{ Herbaceous } & Open shrublands \\
\cline { 2 - 2 } & Woody savannas \\
\cline { 2 - 2 } & Savannas \\
\hline \multirow{2}{*}{ Cultivated land } & Grasslands \\
\cline { 2 - 2 } & Croplands \\
\hline urban & Cropland/Natural vegetation mosaic \\
\hline Ice & Snow and ice \\
\hline Barren & Barren or sparsely vegetated \\
\hline
\end{tabular}

\section{METHOD}

\section{A. Frequency Detection Method}

Two methods are employed to identify the areas of uncertainty. The first method is frequency detection method. Its processing includes a spatial overlay of the generalized datasets to allow a frequency detection of certain kind of land cover. Map in each calendar year is a layer, and the percentage of appearance in all eight layers was counted for each class based on a pixel by pixel calculation. 1 is the full frequency. Pixels with full frequency mean their land cover type kept unchanged from 2001 to 2008. 0.5 means that a pixel had been labeled with certain type four times, with the remaining four years labeled as other types. Frequency maps for each class are displayed in Figure 1.

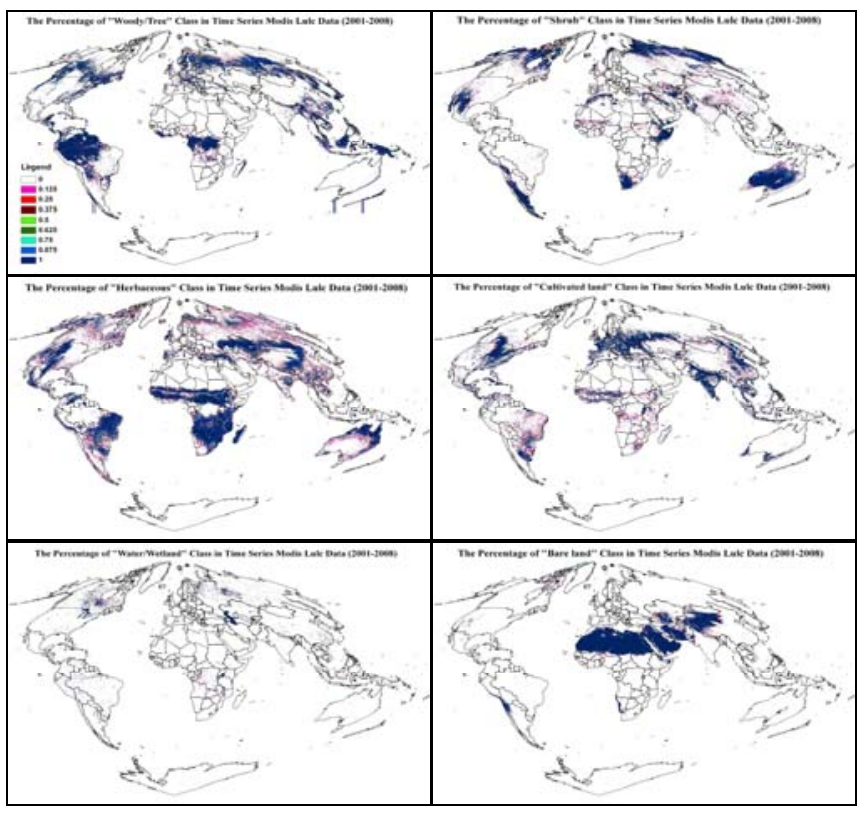




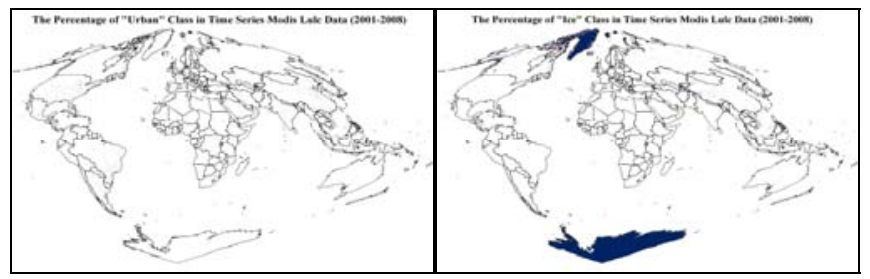

Figure 1. Frequency maps for aggregated land cover classes.

\section{B. Interannual Change Analysis}

The quality of land cover products, especially the datasets been produced using the same data source and classification algorithm can be tested by examining the interannual changes. The Modis Land Cover team utilized posterior probability method to constrain the variation in classification, and final controlled the year-to-year variation to about $10 \%$. However, $10 \%$ change each year must be exaggerated, and surpasses the actual change. The actual land cover change and false changes caused by misclassification are mixed among the changed areas. We will discriminate the two kinds of changes to provide helpful improvements with respect to the knowledge on continental and global land cover issues.

To begin with, we give a definition of change vectors. Each pixel in land cover product owns a change vector, and each vector occupies seven elements. Each element stands for the conversion of land cover types between adjacent year, and conversions between types are assigned with values, which can be looked up in Table 2. The numbers in parentheses after class names are their corresponding labels. To avoid reduplication when differencing the land cover layers across years, values are arranged in geometric sequence. First, layers with original land cover labels were converted to new ones with reassigned labels. Then a differencing calculation was applied to two adjacent years' layers. By checking the value in the result layer, you can tell how the land cover type changed. Eight years' land cover data produces seven result layers. That's why each change vector owns seven elements. Take an example, for a certain pixel, if its land cover type was woody in 2001 and 2002, then changed to shrub in 2003, and keep unchanged in the remaining years, its vector will be $\{0,-1,0,0,0,0,0\}$. -1 is the value representing "woody to shrub" conversion in Table 2. A pixel with all the seven elements zero is defined as an unchanged pixel. Otherwise, it will be labeled as a changed one. Based on this change vector rule, we obtained a map that shows the distribution of changed and unchanged areas (Figure 2).

Comparatively, it is impossible for shrubs or herbaceous grow to trees naturally in one year. Thus, we deem the former change as reasonable change, and the latter one unreasonable. Generally speaking, it is reasonable for long evolved life forms changing to short evolved forms, and natural life forms changing to artificial forms. Some special cases should be considered. Disaster, such as flood, can turn almost every kinds of land cover into water or barren land. Policy would influence the natural changes as well, such as the "Reconverting Cultivated Land into Forest" Policy in china. Besides, due to the rapid climate warming, ice and snow in high mountains, Antarctic and Arctic would melt. Grasslands that been long covered by snow would expose, and some new grasses would grow, which makes the conversion from ice to herbaceous rational. Detailed rules are in Table 2. "N" represents unreasonable change, and vise versa of "Y". Note that, only pixels with all "Y" or zero labels in its change vector can be recognized as areas of reasonable change (ARC) and the remaining areas are areas of unreasonable change

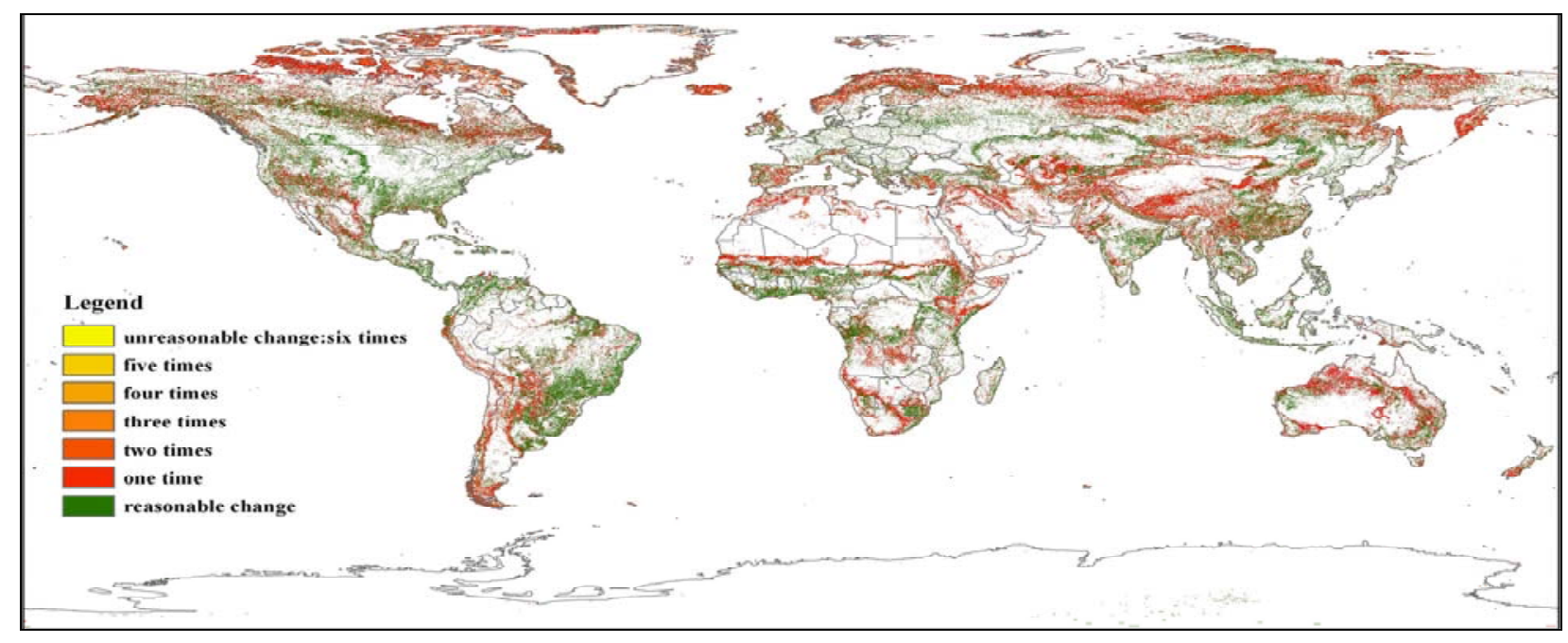

Figure 2. Distribution of ARC and AUC. 
Table 2. Lookup Table for Land Cover Type Conversions

\begin{tabular}{|c|c|c|c|c|c|c|c|c|}
\hline & $\begin{array}{c}\text { Woody } \\
\mathbf{( 1 )}\end{array}$ & $\begin{array}{c}\text { Shrub } \\
\mathbf{( 2 )}\end{array}$ & $\begin{array}{c}\text { Grass } \\
\mathbf{4}\end{array}$ & $\begin{array}{c}\text { Water } \\
(\mathbf{8})\end{array}$ & $\begin{array}{c}\text { Crop } \\
\mathbf{( 1 6})\end{array}$ & $\begin{array}{c}\text { Urban } \\
(\mathbf{3 2})\end{array}$ & $\begin{array}{c}\text { Ice } \\
\mathbf{( 6 4 )}\end{array}$ & $\begin{array}{c}\text { Bare } \\
\mathbf{( 1 2 8 )}\end{array}$ \\
\hline Woody & 0 & $-1(\mathrm{Y})$ & $-3(\mathrm{Y})$ & $-7(\mathrm{Y})$ & $-15(\mathrm{Y})$ & $-31(\mathrm{Y})$ & $-63(\mathrm{~N})$ & $-127(\mathrm{Y})$ \\
\hline Shrub & $1(\mathrm{~N})$ & 0 & $-2(\mathrm{Y})$ & $-6(\mathrm{Y})$ & $-14(\mathrm{Y})$ & $-30(\mathrm{Y})$ & $-62(\mathrm{~N})$ & $-126(\mathrm{Y})$ \\
\hline Grass & $3(\mathrm{~N})$ & $2(\mathrm{~N})$ & 0 & $-4(\mathrm{Y})$ & $-12(\mathrm{Y})$ & $-28(\mathrm{Y})$ & $-60(\mathrm{~N})$ & $-124(\mathrm{Y})$ \\
\hline Water & $7(\mathrm{~N})$ & $6(\mathrm{~N})$ & $4(\mathrm{Y})$ & 0 & $-8(\mathrm{Y})$ & $-24(\mathrm{Y})$ & $-56(\mathrm{~N})$ & $-120(\mathrm{Y})$ \\
\hline Crop & $15(\mathrm{Y})$ & $14(\mathrm{~N})$ & $12(\mathrm{Y})$ & $8(\mathrm{Y})$ & 0 & $-16(\mathrm{Y})$ & $-48(\mathrm{~N})$ & $-112(\mathrm{Y})$ \\
\hline Urban & $31(\mathrm{~N})$ & $30(\mathrm{~N})$ & $28(\mathrm{~N})$ & $24(\mathrm{~N})$ & $16(\mathrm{~N})$ & 0 & $-32(\mathrm{~N})$ & $-96(\mathrm{~N})$ \\
\hline Ice & $63(\mathrm{~N})$ & $62(\mathrm{~N})$ & $60(\mathrm{Y})$ & $56(\mathrm{Y})$ & $48(\mathrm{~N})$ & $32(\mathrm{~N})$ & 0 & $-64(\mathrm{Y})$ \\
\hline Bare & $127(\mathrm{~N})$ & $126(\mathrm{~N})$ & $124(\mathrm{~N})$ & $120(\mathrm{~N})$ & $112(\mathrm{~N})$ & $96(\mathrm{Y})$ & $64(\mathrm{~N})$ & 0 \\
\hline
\end{tabular}

(AUC). Figure 2 shows the distribution of ARC and AUC based on the rules. Green places are ARC, while the yellow and red places are AUC. We divide the degree of unreasonable changes into six levels. Levels represent the times of unreasonable changes presented in the change vector. The higher the lever is, the more ambiguous the classification results are, and more difficulty the area can be classified.

\section{RESUltS}

\section{A. Frequency Maps}

Some general spatial patterns can be observed from the frequency maps (Figure 1). High frequency areas, especially full frequency areas, are mostly large homogeneous regions. For example, the high frequency region of woody is in the tropical rain forest of Brazil, that of shrub is in dryland of Australia, herbaceous is in South Africa, water is in global large lakes, cultivated land is in Europe, north and northeast China plains, and Great plains of North America, ice is in two poles, and bare land is in Sahara Desert, and Arabian peninsula. In contrast with the aggregated and contiguous distribution of full frequency regions, low frequency areas are scattered. Most of them are distributed along edges and transition zones of major ecosystems, such as boreal forest and tundra, savannahs and deserts, as well as major human activity areas, like the major mountain ranges. One explanation is that environment in those regions is unstable, and land cover types can easily change. Another explanation is the difficulties in defining the land cover type of pixels with mixed landscapes. The base algorithm in producing the Collection 5 products is the decision tree method by applying fixed thresholds to separate various classes, which is not well performed in heterogeneous regions. Moreover, the spatial distribution of training sites can be another influencing factor since they are not randomly distributed across the land. For example, the density of training sites in Siberia is obviously much lower compared with America or Europe. Poor training sites will induce poor classification performance. That may be one reason for the bad representation in Siberia.

Except the actual land cover change, a high percentage of full frequency stands for a stable classification. For each class, we draw histograms of the percentage of pixel numbers against their corresponding frequency from 0 to 1 (Figure 3). 100\% frequency stands for an unaltered classification during the eight years, and this percentage of woody, shrub, herbaceous, water, cultivated land, urban, ice and barren are separately $64 \%, 49 \%, 44 \%, 43 \%$, $46 \%, 99 \%, 93 \%$ and $79 \%$. This percentage can highlight the degree of difficulty for a class to be mapped. For example, the full percentage of urban is $99 \%$, which is a successful case. Urban was classified using an ecoreigion-based classification method, and this approach can be adopted in further land cover classification research. Ice and barren land have high percentage as well, since they can be easily separated from other land cover types in both spectral and spatial space. Herbaceous and wetland are particularly problematic due to their lower percent. Herbaceous is scattered in tundra belt in Eurasian steppe, with even more low frequency areas than high frequency areas. The original land cover there is permafrost. Due to the warming climate in recent years, permafrost would be replaced by other types, like grasslands. That may one natural change reason. The low frequency area of woody land is in the transition zone of temperate broadleaf forest biome and taiga biome characterized by coniferous forests in Siberia. Shrub has low full frequency in mountain areas, which may be caused by vegetation seasonal phenology and complex topography in mountain areas. Most full frequency areas of water and wetland are inland large water bodies. Wetlands, especially those are not spatially extensive, will induce substantial errors of omission and commission.

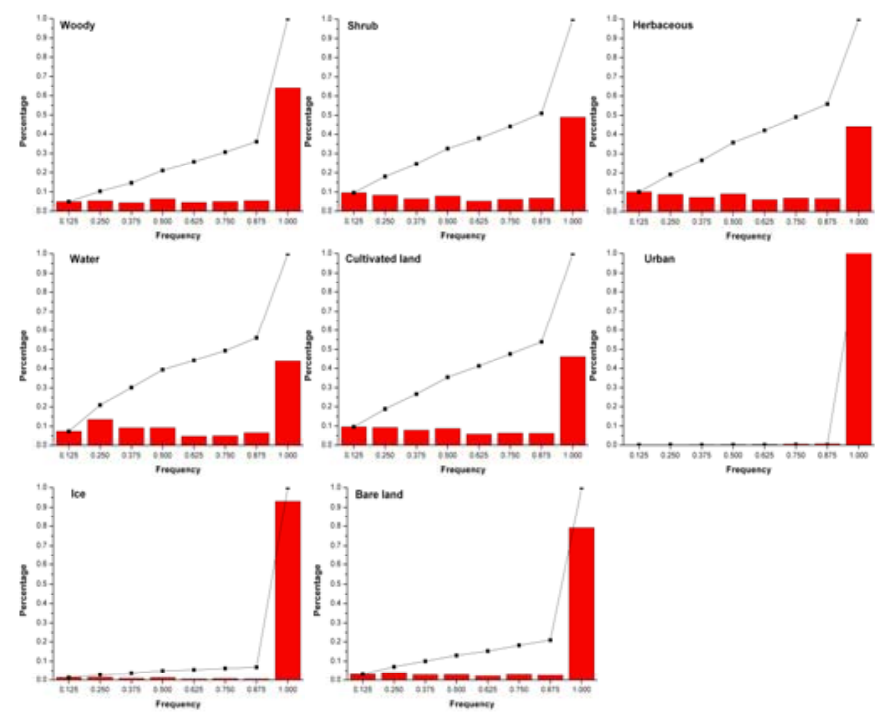

Figure 3. Frequency distribution of the occupancy percentage for each class.

\section{B. Interannual Changes}

Six major regions of AUC occur in (1) middle Siberia extending from North Europe to Eastern Russia; (2) the south boundary of Sahel region in Africa; (3) fringe of Great Victoria desert in Australia; (4) Eastern mountain and plateau regions in America extending from Yukon to Andes. (5) Islands in North Canada. (6) Tibetan plateau. And ARC mainly occurs in: (1) Europe; (2) Western Africa; (3) Southeast Asia; (4) Southern Brazil; (5) Middle America. Compared with ARC, AUC are 
likely to happen in mountain and plateau areas. To prove this, we extracted and compared the elevation of these two kinds of areas (Figure 4). As expected, AUC has a higher proportion in the regions where the altitude is greater than $1000 \mathrm{~m}$. This is rational. The accuracy of most remote sensing products in mountain areas is low. The proportion of AUC is also higher than ARC where the elevation is lower than $100 \mathrm{~m}$. This part concentrates in the edge regions of desert and the Siberia steppe region. Around Great Victoria desert, the most common unreasonable change is from herbaceous to shrub. And in the south boundary of Sahel, the unreasonable conversions are from barren land to shrub, and herbaceous to shrub. The land cover condition is not stable in these two regions, and shrub and herbaceous are hard to discriminate from spectral information. Siberia is the world's largest steppe region encompassing grasslands, shrub, and savanna belts. Due to the complex and unstable environment, it is not appropriate to delineate the clear boundaries of all kinds of land cover types there by applying classification methods used in plains.

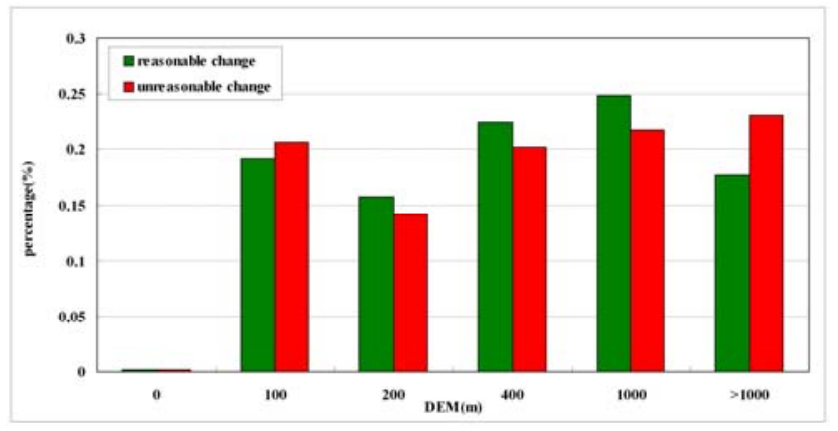

Figure 4. The elevation distribution of reasonable and unreasonable change areas.

Besides the spatial aspect distribution, we would like to investigate which kinds of changes are dominated. Number of interannual change pixels are drawn as vertical axis for each conversion type, and arranged in pairs for visualization convenience (Figure 5). We found the amount of changing pixels is almost equivalent for each pairs. For example, the pixels changed from shrub to barren $(-126)$ has the same quantity level as those changed from barren to shrub (126). This kind of pattern is weird if they all happened naturally. How could it possible for the areas converted between two types keep same each year? Thus we speculate that most changes reflected from the land cover maps are faked. Change types with sharp peaks are: cultivated land \& herbaceous $(-12,12)$, shrub \& herbaceous $(-2,2)$, woody \& herbaceous $(-3,3)$, cultivated land \& woody $(-15,15)$, barren \& shrub $(-126,126)$, water \& woody $(-7,7)$, barren \& herbaceous $(-124,124)$, cultivated land \& shrub $(-14,14)$. Most of the errors in map may be induced from confusion among a subset of ecologically similar classes. The confusion between "herbaceous and cultivated land", "shrub and herbaceous", and 'woody and herbaceous' are most serious. All of them were associated with herbaceous. Those types are mostly encompasses ecological and biophysical gradients, and are quite similar in terms of their spectral-temporal properties.
The quality of classification results each year can also be revealed from the interannual changes. In realistic, the annual changes for most land cover types would not be too much. Thus, if the number of changing pixels is plenty in two neighboring years, especially have sharp contrast with other years, there must have problems. From the line chart, we can see the number of changing pixels in 2005-2004 is fabulous, and 2006-2005 followed. We conclude that land cover data in 2005 is an outlier, since interannual changes containing year 2005 would behave abnormal. In contrast, the magnitude of changes in 2007-2006 and 2008-2007 is smallest. The interannual changes after 2006 are relative small and keep stable. Thus in further studies, if the requirement on time is not too strict, we suggest using land cover data after 2006.

\section{CONCLUSION AND SUGGESTIONS}

Our study has attempted to assess the mapping uncertainties in Modis Collection 5 global land cover product. From the frequency detection method, we learnt that areas with stable land cover types (full frequency areas) are mostly contiguous distributed in large homogeneous regions, while unstable areas with low frequency are scattering distributed along edges and transition zones of major ecosystems. From the interannual changes, we found herbaceous occupies a large proportion in changing areas. Six major regions that unreasonable changes would most likely happen and five regions for reasonable changes were concluded. Mountains and transition areas where remote sensing classification is difficult are likely to have more AUC. Dominate changing types can also be observed from the interannual change curves. Most of them are types that are confusion and highly mixable in feature space. The changed types in pairs also proved most changed areas in land cover dataset are faked. And for insurance, we suggest using Modis land cover data after 2006.

As mentioned in the introduction, clear understanding of the obscure and difficult areas in classification is crucial for both data producers and users. Thus validation is a crucial step when completing a global land cover map. The best way to measure accuracy is using ground sampling sites. But it is hard to maintain both the training sites and test sites at a global scale. Modis Collection 5 land cover product had performed a 10 fold cross-validation analysis using the training site database, and no design-based sampling was carried out. However, lots of works had been carried out at regional or continental scale. Some of them have field survey oriented at specific land cover types. Those information should be aggregated together to build up a public validation database.

Remote sensing has been advocated as a means of producing more consistent, repeatable and unbiased products than were previously possible with traditional ground-based methods. Although a tremendous amount of research has been devoted to land cover mapping, and accuracy received great improvements, the present capability in producing accurate land cover maps over large areas is far from satisfactory. Some difficult areas or 


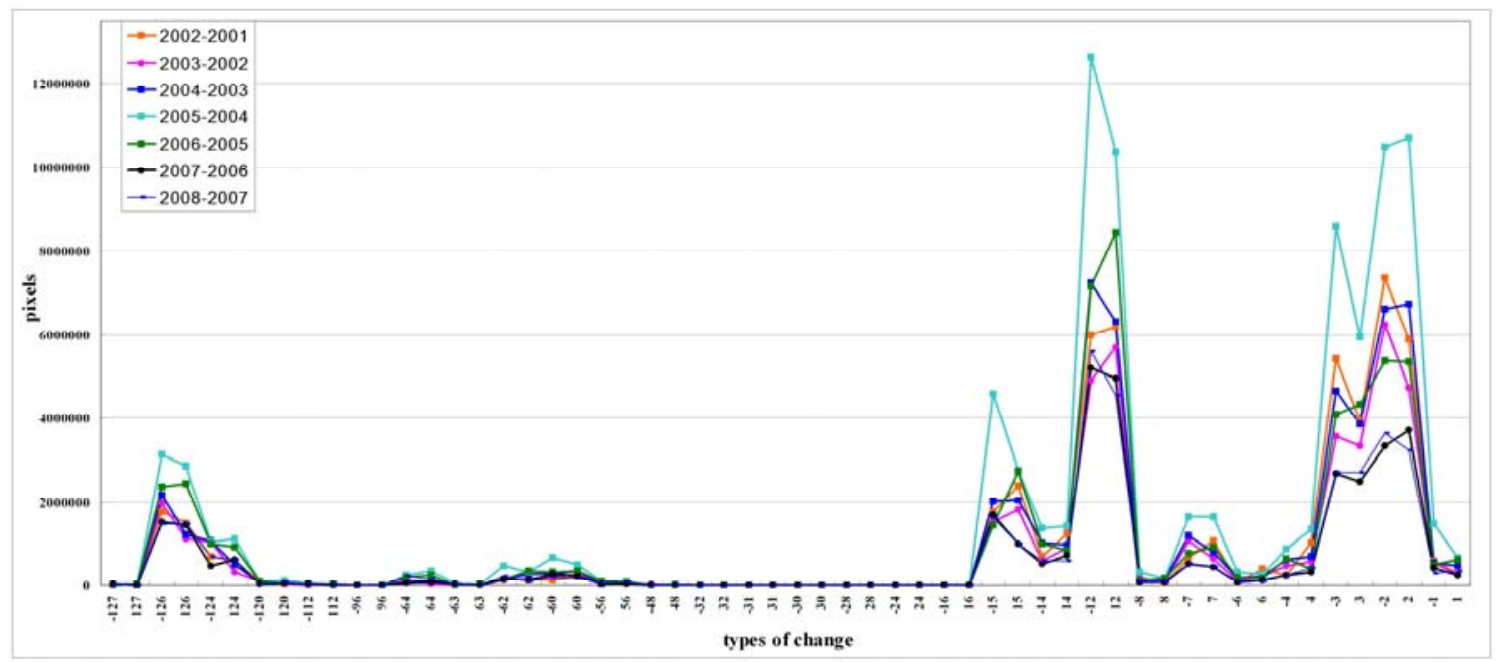

Figure 5. Interannual changes of modis land cover data.

types are still unsolved, and major mistakes are repeating in different products that produced by different organizations. Thus, through this study, we hope the further map producers could focus on important regions and land cover types. Special classification methods or tools, and different input data should be developed and prepared to solve those problems. More surveys should be carried out in problematic areas to sample more training sites. And thematic maps should be made best use. Since some land cover types are consistently poorly classified by general classifiers, class oriented approached should be developed to produce individual land cover maps.

\section{REFERENCES}

[1] O.E. Sala, I.F.S. Chapin, J.J. Armesto, E. Berlow, J. Bloomfield, R. Dirzo, et al, "Global biodiversity scenarios for the year 2100," Science,2000, 287 (5459), pp. 1770-1774.

[2] A.J. Hansen, R.P. Neilson, V.H. Dale, C.H. Flather, L.R. Iverson, D. J.Currie, et al., "Global change in forests: responses of species, communities, and biomes," Bioscience, 2001, 51 (9), pp. 765-779.

[3] J.M.J. Travis, "Climate change and habitat destruction: a deadly anthropogenic cocktail,” Proc. R. Soc. B-Biological Sciences, 2003, 270, pp. $467-473$.

[4] A. Fischlin, G.F. Midgley, J.T. Price, R. Leemans,B. Gopal;C. Turley, et al, "Ecosystems, their properties, goods and services," Cambridge University Press, Cambridge, UK, 2007, pp. 211-272.

[5] F.S. Chapin III, E.S. Zavaleta, V.T. Eviner, R.L. Naylor, P.M. Vitousek, H.L. Reynolds, et al., "Consequences of changing biodiversity," Nature, 2000,405, pp.234-242.

[6] W. Jetz, D.S. Wilcove, A.P. Dobson, "Projected impacts of climate and land-Use change on the global diversity of birds," PLoS Biol, 2007,5(6).

[7] C.C. Nicholas, A.W. Michael, I. Donald. "Exploring the relative importance of satellite-derived descriptors of production, topography and land cover for predicting breeding bird species richness over Ontario, Canada," Rem. Sens. Environ., 113(3), pp.668-679.

[8] R. Raquel, S. Xavier, S. Neftali, M.A. Carretero, G.A. Llorente, "Biodiversity and land uses at a regional scale: Is agriculture the biggest threat for reptile assemblages?"Acta Oecologica, 2009, 35(2), pp.327-334
J. Scepan, "Thematic validation of high-resolution global land-cover data sets," PE\&RS, 1999,659, pp.1051-1060.

[9] P. Mayaux, H. Eva, J. Gallego, A.H. Strahler, M. Herold, S. Agrawal, et al. "Validation of the global land cover 2000 map," IEEE Trans. Geosci. Rem. Sens., 2006, 44(7), pp.1728-1739.

[10] MODIS land cover team (2003). Validation of the consistent year 2003 V003 MODIS land cover product Available at: http://geography.bu.edu/landcover/userguidelc/consistent.htm

[11] F. Sedano, P. Gong, M. Ferrao, "Land cover assessment with MODIS imagery in Southern African Miombo ecosysterns," Rem. Sens. Environ., 2005, 98(4),pp.429-441

[12] K.E. Frey, L.C. Smith, "How well do we know northern land cover? Comparison of four global vegetation and wetland products with a new ground-truth database for West Siberia," Global Biogeochem. Cycles, 2007.

[13] P. Gong. "Accuracies of global land cover maps checked against Fluxnet sites," Science Foundation in China, 16(1):31-35.

[14] C. Giri, Z. Zhu, B. Reed, "A comparative analysis of the global land cover 2000 and MODIS land cover data sets," Rem. Sens. Environ., 2005, 94, pp.123-132.

[15] I. McCallum, M. Obersteiner, S. Nilsson, A. Shvidenko, "A spatial comparison of four satellite derived $1 \mathrm{~km}$ global land cover datasets," Int. J. Appl. Earth Observ. Geoinform., 2006, 8(4), pp.246-255.

[16] M.C. Hansen, B. Reed, "A comparison of the IGBP DISCover and University of Maryland $1 \mathrm{~km}$ global land cover products," Int. J. Rem. Sens., 2000, 21, pp.1365-1373.

[17] M. Herold, P. Mayaux, C.E. Woodcock, A. Baccini, C. Schmullius, "Some challenges in global land cover mapping: An assessment of agreement and accuracy in existing $1 \mathrm{~km}$ datasets," Rem. Sens. Environ., 2008, 112(5), pp. $2538-2556$

[18] T.R. Loveland and A.S. Belward, "The IGBP-DIS global $1 \mathrm{~km}$ land cover data set, DISCover: First results,” Int. J. Rem. Sens., 1997,18, pp.32913295.

[19] P.A. Matson and D.S. Ojima. "Terrestrial Biosphere Exchange with Global Atmospheric Chemistry," IGBP Report No. 13. Stockholm. 1990.

[20] M.A. Friedl, M.S. Damien, B. Tan, A. Schneider, N. Ramankutty, A. Sibley, et al, "Modis collection 5 global land cover: Algorithm refinements and characterization of new datasets," Rem. Sens. Environ., 2010,114 (1),pp.168-182. 